\title{
Perilaku Pemberian ASI Eksklusif Dikaitkan dengan Pengelolaan Laktasi Selama Persalinan
}

\author{
Hema Dewi Anggraini \\ Fakultas Kedokteran, Universitas Muhammadiyah Semarang \\ Jl. Kedungmundu Raya No.18, Semarang, 50273 \\ Email: hemadewi@gmail.com
}

\begin{abstract}
ABSTRAK
Salah satu faktor yang mungkin berkaitan dengan pemberian ASI eksklusif adalah pengelolaan laktasi selama persalinan. Fasilitas penyedia pelayanan persalinan bertanggung jawab memberikan pengelolaan laktasi yang baik bagi ibu bersalin. Tujuan penelitian ini untuk mengetahui hubungan pengelolaan laktasi selama persalinan dengan perilaku pemberian ASI eksklusif. Penelitian di Dusun Dukuturi Kabupaten Tegal dengan desain cross sectional menggunakan teknik wawancara terhadap pasien pada Oktober 2016. Jumlah sampel 83 responden yang memenuhi kriteria inklusi dan eksklusi. Pengelolaan laktasi diukur menggunakan kuesioner yang sebelumnya telah dilakukan uji validitas dan reliabilitas. Uji statistik menggunakan chi square untuk menjelaskan hubungan dari variabel bebas terhadap variabel terikat. Rata-rata responden berumur 29 tahun, dengan 74,7\% ibu tidak memberikan ASI eksklusif. Hasil uji chi square menyebutkan bahwa tidak terdapat hubungan yang signifikan antara pelayanan rooming in, skin to skin contact $\geq 1$ jam setelah persalinan, penjelasan proses dan teknik menyusui, praktik teknik menyusui, inisiasi menyusu dini, dan ibu bayi tidak terpisah lebih 2 jam setelah persalinan terhadap pemberian ASI eksklusif. Rata-rata penyedia pelayanan persalinan saat ini sudah menerapkan pengelolaan laktasi yang baik. Kemungkinan terdapat faktor lain yang belum diteliti yang mempengaruhi perilaku pemberian ASI eksklusif, antara lain kondisi bayi, pengetahuan ibu, pengelolaan laktasi ibu setelah persalinan, pengaruh lingkungan, dan lain-lain.
\end{abstract}

Kata kunci: Pengelolaan Laktasi, Pemberian ASI Eksklusif

\section{Exclusive Breast-Feeding Behavior Associated with Lactation Management During Birth Process}

\begin{abstract}
One of the factor that may be related to maternal behavior in exclusive breastfeeding is how lactation management during labor. The purpose of this study was to determine the relationship of lactation management during labor with exclusive breastfeeding behavior.The cross sectional study was conducted in DukuturiVillage Tegal Regency, applying interview technique for data collection in October 2016. As many as 83 were recruited based on inclusion and exclusion criteria. Lactation management was measured using a questionnaire that had previously been tested for validity and reliability. Statistical test used chi square to explain the relationship of independent variable to dependent variable.The age average of respondent was 29 years old. Majority of respondent $(74,7 \%)$ did not give exclusive breastfeeding. The chi square test showed that there is no significant correlation between rooming in, skin to skin contact $\geq 1$ hour after delivery, explanation of breastfeeding process and techniques, the practice of breastfeeding techniques, early breastfeeding initiation, and infant and mothernot separated more than 2 hours after delivery and exclusive breastfeeding. There may be other factors affecting exclusive breastfeeding behaviors, including maternal knowledge, family support, environmental influences, and so on.The average of delivery service provider is currently implementing good lactation management.
\end{abstract}

Keyword: Lactation Management, Exclusive Breast-Feeding 


\section{Pendahuluan}

Pemberian ASI eksklusif sangat berpengaruh dan mengandung banyak keuntungan bagi ibu dan anak. ASI dapat mencegah penyakit kronik, mengurangi angka infrksi saluran pencernaan, morbiditas, serta meningkatkan pertumbuhan dan perkembangan anak. Pengaruh pada ibu yang menyusui dapat menunda kesuburan, mengurangi risiko perdarahan postpartum, mempercepat pengembalian berat badan seperti sebelum melahirkan, serta menurunkan risiko kanker ovarium dan payudara. ${ }^{1}$

Pada tahun 2001, WHO merekomendasikan bayi berumur 0-6 bulan hanya memerlukan ASI saja atau yang disebut ASI eksklusif. ASI sudah memenuhi seluruh kebutuhan nutrisi bayi usia 0-6 bulan. Selain nutrisi yang dapat menjamin pertumbuhan dan perkembangan bayi, ASI juga mengandung komponen yang dibutuhkan untuk kekebalan tubuhnya hingga dewasa kelak. Setelah 6 bulan, bayi akan mendapatkan tambahan MPASI (makanan pendamping ASI). Pemberian ASI tetap dianjurkan pada bayi sampai usia 2 tahun. ${ }^{2,3}$

Pemberian ASI eksklusif dipengaruhi oleh banyak faktor. Faktor-faktor tersebut berkaitan dengan usia, tingkat pengetahuan, pendidikan, pekerjaan, dukungan keluarga, pengelolaan laktasi selama persalinan, serta pengelolaan laktasi setelah persalinan. ${ }^{1,7}$ Salah satu faktor yang berperan yaitu pengelolaan laktasi yang diberikan oleh fasilitas pelayanan kesehatan selama persalinan. Penelitian yang dilakukan oleh Mikiel-Kostyra et al dan Leena Hanula et al menyebutkan bahwa pengelolaan laktasi selama persalinan merupakan hal positif yang dapat meningkatkan durasi pemberian ASI eksklusif. ${ }^{3,4}$ Titik berat pengelolaan laktasi dalam penelitian tersebut berkaitan dengan meningkatnya pengetahuan ibu akan pentingnya ASI eksklusif dan edukasi praktik menyusui yang benar, sehingga ibu terampil, termotivasi dan percaya diri dalam menyusui bayinya. Dukungan dalam menyusui yang diberikan oleh fasilitas kesehatan penyedia layanan persalinan disertai dengan dukungan keluarga yang optimal akan mempengaruhi perilaku ibu dalam pemberian ASI eksklusif. ${ }^{3}$

Sebagian besar fasilitas pelayanan kesehatan yang memberikan pelayanan persalinan, saat ini sudah menerapkan konsep sayang ibu dan anak. Konsep tersebut mencakup 10 langkah dalam keberhasilan menyusui. Pengelolaan laktasi yang baik mengacu dari 10 langkah keberhasilan menyusui tersebut merupakan langkah awal yang menginisiasi keberhasilan pemberian ASI eksklusif. Pengelolaan laktasi tersebut antara lain pelayanan rooming in, skin to skin contact $\geq 1$ jam setelah persalinan, penjelasan proses dan teknik menyusui, praktik teknik menyusui, penjelasan inisiasi menyusu dini, dan perlakuan ibu bayi tidak terpisah lebih 2 jam setelah persalinan. ${ }^{2,5,7}$

Dusun Dukuturi Kabupaten Tegal merupakan daerah dengan jumlah balita cukup banyak, namun sebagian besar tidak mendapatkan ASI eksklusif. Berdasarkan wawancara dengan kader setempat, menyampaikan bahwa sebagian besar balita tidak mendapatkan ASI eksklusif bahkan banyak pula yang tidak menyusui bayinya. 
Melihat permasalahan tersebut, peneliti tertarik untuk meneliti faktor pengelolaan laktasi selama persalinan pada ibu yang memiliki balita usia $1-4$ tahun di desa tersebut. Tujuan penelitian ini untuk mengetahui hubungan pengelolaan laktasi selama persalinan dengan perilaku pemberian ASI eksklusif. Faktor pengelolaan laktasi selama persalinan menjadi menarik untuk diteliti karena merupakan inisiasi keberhasilan menyusui walaupun tidak mutlak, dan tanpa mengesampingkan faktor faktor lainnya.

\section{Metode Penelitian}

Jenis penelitian yang digunakan adalah penelitian observasional analitik kuantitatif, dengan disain Cross Sectional. Subjek dalam penelitian ini adalah ibu yang memiliki balita 14 tahun dengan kriteria inklusi yaitu ibu dengan anak yang lahir sehat/bugar, status gizi anak baik dan kriteria eksklusi apabila ibu tidak bersedia sebagai responden dan tidak kooperatif. Berdasarkan kriteria tersebut ditemukan jumlah populasi sebanyak 83 ibu dan karena jumlah populasi kurang dari 100 maka seluruh populasi menjadi responden dalam penelitian ini (total sampling). Pengumpulan data dilakukan dengan wawancara menggunakan kuesioner terstruktur, yang telah diuji validitas dan reliabilitasnya. Variabel bebas dalam penelitian ini adalah pengelolaan laktasi selama persalinan meliputi: pelayanan rooming in, skin to skin contact $\geq 1$ jam setelah persalinan, penjelasan proses dan teknik menyusui, praktik teknik menyusui, penjelasan inisiasi menyusu dini, dan perlakuan ibu bayi tidak terpisah lebih
2 jam setelah persalinan. Sedangkan variabel terikatnya adalah pemberian ASI eksklusif. Analisis data dilakukan dengan Uji Chi Square. Pengolahan data menggunakan SPSS for Windows.

\section{Hasil}

Deskripsi karakteristik responden meliputi umur ibu, tingkat pendidikan, teknik persalinan, dan yang memberikan ASI eksklusif. Rata-rata usia responden 29 tahun.

Tabel 1. Karakteristik Responden

\begin{tabular}{|c|c|c|}
\hline Karakteristik & $\mathbf{n}$ & $\%$ \\
\hline \multicolumn{3}{|l|}{ Tingkat Pendidikan Ibu } \\
\hline$-\quad \mathrm{SD}$ & 17 & 20,5 \\
\hline - $\quad$ SLTP & 22 & 26,5 \\
\hline - $\quad$ SLTA & 22 & 26,5 \\
\hline - PT & 22 & 26,5 \\
\hline \multicolumn{3}{|l|}{ Teknik Persalinan } \\
\hline - $\quad$ Spontan & 67 & 80,7 \\
\hline $\begin{array}{l}\text { - Tindakan (vakum, } \\
\text { forceps) }\end{array}$ & 6 & 7,2 \\
\hline Operasi SC & 10 & 12 \\
\hline \multicolumn{3}{|l|}{ Pemberian ASI Eksklusif } \\
\hline$-\quad \mathrm{Ya}$ & 21 & 25,3 \\
\hline - $\quad$ Tidak & 62 & 74,7 \\
\hline
\end{tabular}

Tabel 1 menunjukkan bahwa sebagian besar responden berlatar belakang pendidikan minimal SLTP, teknik persalinan spontan sebesar 80,7\%, dan 75\% tidak memberikan ASI eksklusif.

Tabel 2. Pengelolaan laktasi selama persalinan

\begin{tabular}{lcc} 
Jenis pelayanan & n & $\%$ \\
\hline Rooming in & 76 & 91,6 \\
$-\quad$ Ya & 7 & 8,4 \\
$-\quad$ Tidak & & \\
\hline $\begin{array}{l}\text { Skin to skin contact } \geq \mathbf{1} \\
\text { jam setelah persalinan }\end{array}$ & & \\
$-\quad$ Ya & 78 & 94 \\
$-\quad$ Tidak & 5 & 6 \\
\hline $\begin{array}{l}\text { Penjelasan proses dan } \\
\text { teknik menyusui }\end{array}$ & & \\
$-\quad$ Ya & 80 & 96,4 \\
\hline
\end{tabular}




\begin{tabular}{ccc}
\hline$-\quad$ Tidak & 3 & 3,6 \\
\hline $\begin{array}{c}\text { Praktik teknik menyusui } \\
-\quad \text { Ya }\end{array}$ & 79 & 95,2 \\
$-\quad$ Tidak & 4 & 4,8 \\
\hline $\begin{array}{l}\text { Penjelasan inisiasi } \\
\text { menyusu dini } \\
-\quad \text { Ya }\end{array}$ & 78 & 94 \\
$-\quad$ Tidak & 5 & 6 \\
\hline $\begin{array}{l}\text { Perlakuan ibu bayi tidak } \\
\text { terpisah lebih 2 jam } \\
\text { setelah persalinan }\end{array}$ & & \\
$-\quad$ Ya & 7 & 8,4 \\
$-\quad$ Tidak & 76 & 91,6 \\
\hline
\end{tabular}

Tabel 2 menunjukkan pengelolaan laktasi oleh fasilitas kesehatan selama persalinan. Sebagian besar responden mendapatkan pengelolaan rooming in, skin to skin contact $\geq 1$ jam setelah persalinan, penjelasan proses dan teknik menyusui, praktik teknik menyusui, penjelasan inisiasi menyusu dini, dan perlakuan ibu bayi tidak terpisah lebih 2 jam setelah persalinan.

Tabel 3 menunjukkan analisis pengelolaan laktasi selama persalinan dengan pemberian ASI eksklusif. Tidak ada hubungan yang sinifikan antara pengelolaan rooming in, skin to skin contact $\geq 1$ jam setelah persalinan, penjelasan proses dan teknik menyusui, praktik teknik menyusui, penjelasan inisiasi menyusu dini, dan perlakuan ibu bayi tidak terpisah lebih 2 jam setelah persalinan terhadap pemberian ASI eksklusif.

Tabel 3. Analisis pengelolaan laktasi selama persalinan terhadap pemberian ASI eksklusif

\begin{tabular}{|c|c|c|c|}
\hline \multirow[b]{2}{*}{ Jenis pelayanan } & \multicolumn{2}{|c|}{ Pemberian ASI eksklusif } & \multirow[b]{2}{*}{$p$-value } \\
\hline & $\begin{array}{c}\mathrm{Ya} \\
(\mathrm{n}=21)\end{array}$ & $\begin{array}{l}\text { Tidak } \\
(\mathrm{n}=62)\end{array}$ & \\
\hline \multicolumn{4}{|l|}{ Rooming in } \\
\hline$-\quad Y a$ & $20(26,3 \%)$ & $56(73,7 \%)$ & 0,484 \\
\hline - $\quad$ Tidak & $1(14,3 \%)$ & $6(85,7 \%)$ & \\
\hline \multicolumn{3}{|l|}{$\begin{array}{l}\text { Skin to } \text { skin contact } \geq 1 \text { jam } \\
\text { setelah persalinan }\end{array}$} & \\
\hline - Ya & $21(26,9 \%)$ & $57(73,1 \%)$ & 0,179 \\
\hline - $\quad$ Tidak & $0(0 \%)$ & $5(100 \%)$ & \\
\hline \multicolumn{3}{|l|}{$\begin{array}{l}\text { Penjelasan proses dan teknik } \\
\text { menyusui }\end{array}$} & \\
\hline$-\quad Y a$ & $20(25 \%)$ & $60(75 \%)$ & 0,744 \\
\hline - $\quad$ Tidak & $1(33,3 \%)$ & $2(66,7 \%)$ & \\
\hline \multicolumn{3}{|l|}{ Praktik teknik menyusui } & \\
\hline$-\mathrm{Ya}$ & $20(25,3 \%)$ & $59(74,7 \%)$ & 0,989 \\
\hline - $\quad$ Tidak & $1(25 \%)$ & $3(75 \%)$ & \\
\hline \multicolumn{3}{|l|}{$\begin{array}{l}\text { Penjelasan inisiasi menyusu } \\
\text { dini }\end{array}$} & \\
\hline$-Y a$ & $20(25,6 \%)$ & $58(74,4 \%)$ & 0,799 \\
\hline - $\quad$ Tidak & $1(20 \%)$ & $4(80 \%)$ & \\
\hline $\begin{array}{l}\text { Perlakuan ibu bayi tidak } \\
\text { terpisah lebih } 2 \text { jam setelah } \\
\text { persalinan } \\
\text { - Ya } \\
\text { - Tidak }\end{array}$ & $\begin{array}{c}1(14,3 \%) \\
20(26,3 \%)\end{array}$ & $\begin{array}{c}6(85,7 \%) \\
56(73,7 \%)\end{array}$ & 0,484 \\
\hline
\end{tabular}




\section{Pembahasan}

Penelitian ini dengan jumlah responden yang sangat terbatas sehingga menghasilkan variasi yang cenderung ke arah homogen dan berimplikasi ke pengujian hipotesis yang tidak terbukti. Berkenaan dengan hasil ini maka pembahasan dalam diskusi ini lebih mendasarkan pada hasil analisis univariat daripada hasil analisis bivariat karena semua hipotesis yang ada tidak satupun yang terbukti.

Berdasarkan hasil analisis univariat ditemukan bahwa sebagian besar responden (75\%) pada penelitian ini tidak memberikan ASI eksklusif untuk bayinya. Hal tersebut hampir sama dengan beberapa penelitian lain tentang perilaku pemberian ASI eksklusif yang menyebutkan bahwa angka pemberian ASI eksklusif rata-rata menurun dari usia bayi 4 bulan hingga 30-50\%, dan pada usia 6 bulan hingga 70-80\%.

Hasil penelitian ini menunjukkan bahwa tidak terdapat hubungan yang signifikan antara pengelolaan laktasi oleh fasilitas penyedia layanan persalinan selama proses persalinan terhadap perilaku ibu dalam pemberian ASI eksklusif. Hal tersebut sesuai pula dengan hasil penelitian yang dilakukan oleh DiGirolamo et al yang menyebutkan bahwa tidak ada hubungan yang signifikan antara pelayanan laktasi yang meliputi praktik inisiasi menyusu dini selama 1 jam, rooming in, menyusui semau anak, tidak memberikan pacifiers dalam menyusui, memberikan informasi dan dukungan dalam menyusui, serta hanya memberikan ASI saja. Namun pada penelitian tersebut menyebutkan bahwa ibu dengan inisiasi menyusu dini selama 1 jam, hanya memberikan ASI saja, serta tidak memberikan pacifiers berkaitan dengan pemberian ASI eksklusif dengan durasi di atas 6 minggu. Bagi ibu yang tidak mendapatkan pengelolaan laktasi tersebut berpotensi 13 kali lebih cepat menghentikan proses menyusui ${ }^{5}$

Penelitian ini menunjukkan bahwa sebagian besar ibu (>90\%), sudah mendapatkan pelayanan pengelolaan laktasi yang baik selama persalinannya. Hal ini menunjukkan bahwa kebijakan pemerintah tentang dukungan menyusui dapat diterapkan di hampir seluruh fasilitas kesehatan penyedia layanan persalinan. Hanya saja yang perlu dievaluasi adalah bagaimana penerapan kebijakan tersebut apakah sudah mencapai target untuk meningkatkan kesadaran dan pengetahuan ibu mengenai pentingnya ASI eksklusif dan tetap menyusui bayinya sampai berusia 2 tahun.

Hasil penelitian ini menunjukkan walaupun sebagian besar ibu sudah mendapatkan pelayanan pengelolaan laktasi yang baik, namun angka pemberian ASI eksklusif cukup rendah (25\%). Kemungkinan penerapan pelayanan laktasi yang dilakukan oleh fasilitas kesehatan penyedia layanan persalinan masih sebatas prosedural yang dijalankan saja, namun belum sampai kepada tujuan bahwa intervensi yang diberikan dapat mengubah perilaku ibu dengan meningkatkan pengetahuan dan ketrampilannya tentang menyusui, serta solusi terhadap ibu apabila mengalami kesulitan pada proses menyusui ${ }^{7}$ Perlu dilakukan penelitian evaluasi lebih lanjut tentang praktik pelayanan pengelolaan laktasi 
di fasilitas kesehatan penyedia layanan persalinan.

Faktor lain yang mungkin berpengaruh dalam praktik pemberian ASI eksklusif selain faktor pengelolaan laktasi selama persalinan. Faktor lain tersebut antara lain tingkat pengetahuan ibu, ibu belum terampil dalam menyusui setelah persalinan, kurangnya dukungan keluarga, ibu bekerja, serta tidak adanya follow up setelah persalinan dari fasilitas kesehatan tentang proses menyusui. ${ }^{1-6,}$ 8,9

\section{Kesimpulan dan Saran}

Berdasarkan hasil penelitian sebagian besar $(75 \%)$ ibu tidak memberikan ASI eksklusif. Pengelolaan laktasi selama proses persalinan pada fasilitas kesehatan mayoritas sudah dilaksanakan (lebih dari 90\%) kecuali pada aspek perlakuan ibu bayi tidak terpisah lebih 2 jam setelah persalinan dimana baru terlaksana $8 \%$ saja. Hasil analisis bivariat tidak ada variabel yang berhubungan dengan pemberian ASI eksklusif.

Seluruh hipotesis dalam penelitian ini tidak terbukti sangat dimungkinkan karena terbatasnya responden dan variabel yang ditemukan cenderung homogen. Namun demikian kemungkinan terdapat faktor lain yang belum diteliti yang mempengaruhi perilaku pemberian ASI eksklusif, antara lain kondisi bayi, pengetahuan ibu, pengelolaan laktasi ibu setelah persalinan, pengaruh lingkungan, dan lain-lain. Perlu dilakukan penelitian evaluasi lebih lanjut tentang praktik pelayanan pengelolaan laktasi di fasilitas kesehatan penyedia layanan persalinan, serta faktor-faktor lain yang mempengaruhi pemberian ASI eksklusif.

\section{Daftar Pustaka}

1. Jessri M, Farmer AP, Maximova K, Willows ND, Bell RC. Predictors of exclusive breastfeeding : observations from the Alberta pregnancy outcomes and nutrition ( APrON ) study. BMC Pediatrics. $2013 ; 1377$

2. Wambach K. Clinical Lactation Practice: 20 Years of Evidence. J Hum Lact [Internet]. 2005;21(3):245-58. Available from:

http://jhl.sagepub.com/cgi/doi/10.1177/089 0334405279001

3. Hannula L, Kaunonen M, Tarkka MT. A systematic review of professional support interventions for breastfeeding. J Clin Nurs. 2008;17(9):1132-43.

4. Mikiel-Kostyra K, Mazur J, Bołtruszko I. Effect of early skin-to-skin contact after delivery on duration of breastfeeding: a prospective cohort study. Acta Paediatr [Internet]. 2002;91(12):1301-6. Available from:

http://www.ncbi.nlm.nih.gov/pubmed/125 78285

5. DiGirolamo AM, Grummer-Strawn LM, Fein SB. Effect of maternity-care practices on breastfeeding. Pediatrics. 2008;122 Suppl(October):S43-9.

6. Wan H, Tiansawad S, Yimyam S, Sriaporn P. Factors Predicting Exclusive Breastfeeding among The First Time Chinese Mothers. Pacific Rim Int J Nurs Res. 2015;(March):19(1)32-44. 
7. Anggraheny HD, Sudiro. Jurnal Kesehatan Masyarakat. The childbirth services aspect that influence patient satisfaction. 2017;12(2).

8. Dykes F, Moran V, Burt S, Edwards J. Adolescent mothers and breastfeeding: experiences and support-needs - an exploratory study. J Hum Lact. 2003;19(4):391-401.

9. Dewey KG, Nommsen-rivers LA, Heinig MJ, Cohen RJ. Risk factors for suboptimal infant breastfeeding behavior, delayed onset of lactation, and excess neonatal weight loss. Pediatrics. 2003;112(3).

10. Ministry of Health Republic of Indonesia. Situation and analysis of exclusive breastfeeding. [Internet] 2014; 1-7. Avalaible from http://www.depkes.go.id/resources/downlo ad/pusdatin/infodatin/infodatin-asi.pdf 